\title{
Early Diagnosis of Difficulties or Disorders of a 0 to 6 Year-Old Child in Italian Nursery Schools and Kindergartens*
}

\author{
Silvia Maggiolini \\ Università Cattolica del Sacro Cuore, Milan, Italy; \\ CeDisMa (Research Centre on Disability and Marginality), Università Cattolica del Sacro Cuore, Milan, Italy
}

\begin{abstract}
Along with the EU directive on early childhood education, and considering recent advances in Neuroscience, CeDisMa—Research Centre on Disability and Marginality (Università Cattolica del Sacro Cuore, Milan, Italy) — has carried out an action research project focused on identifying the main educational models used in early education services, as well as possible tools for analysis and early diagnosis of disorders or difficulties of children attending Nursery schools and Kindergartens.
\end{abstract}

Keywords: early intervention, special education, in-service training, educational co-responsibility

\section{Introduction}

Recent studies in Neuroscience have promoted a better understanding of the development of brain structures, and have emphasised the role of early educational intervention for the cognitive, linguistic, emotional and relational development of children (Rushton, Rushton, \& Larkin, 2010; Shonkoff, 2010; Shonkoff \& Phillips, 2000). In the light of the aforementioned research, the importance of quality educational interventions — advocated by educators and teachers for a long time—-is now grounded in scientific evidence.

In particular, these studies show that the new-born's first experiences, since the very first life moments-along with his/her genetic heritage-are fundamental for later stages of development. Professor Shonkoff, Director of the Center on Developing Child at Harvard University, and his research group highlight the close relationship between the nursing actions and the educational processes implemented (Shonkoff, 2010).

The ways in which adults care for a child, thanks to a wide range of stimuli (verbal and non-verbal communication), have a significant influence on the child development's process, not only in terms of skills, but also in the construction of a strong and well-structured personality.

In light of these achievements—and along with the EU Recommendation policy for the quality improvement in early childhood education services (EU Recommendation 92/241/EEC; Urban \& Vandenbroek, 2011) —CeDisMa, Research Centre on Disability and Marginality ${ }^{1}$ (Università Cattolica del Sacro Cuore, Milan, Italy), has carried out a multi-phase research project that put together the experiences of two different

\footnotetext{
*Acknowledgements: Special thanks to Happy Child srl, FISM Parma (Federazione Italiana Scuole Materne), to the teachers and educators who joined the research, and to the CeDisMa research group (Luigi d'Alonzo, Barbara Perin, Elena Zanfroni, Gianni Zampieri, Luisa Costantino, Irene Gottoli).

Silvia Maggiolini, Ph.D., Researcher in Special Education, Università Cattolica del Sacro Cuore, Milan (Italy); Member of CeDisMa (Research Centre on Disability and Marginality), Università Cattolica del Sacro Cuore, Milan (Italy).

${ }^{1}$ Retrieved from http://centridiricerca.unicatt.it/cedisma
} 
Italian Nursery schools and Kindergartens ${ }^{2}$ settings. The study intended to lead to a definition of possible tools for the analysis and the early diagnosis of disorders or difficulties in pre-school children in order to improve not only the school inclusion process, but also the quality of life of people with disabilities and their families.

\section{The Research Design}

The Italian model, which promotes educational inclusion for individuals with disabilities (law 118/1971 and 517/1977), boasts over 40 years of ground-breaking experimental work-both theoretical and applied. Drawing on pioneering pedagogical values that are now internationally recognised, Italy has been one of the first countries in the world to promote the inclusion of students with disability into mainstream educational provision (Maggiolini \& Molteni, 2013).

The importance that pre-school age is increasingly gaining in pedagogical field led CeDisMa research group to investigate the intervention in early years in order to support and to enhance the schools' inclusion process of young children with disabilities or difficulties. How can the quality of early childhood services be improved? How can teachers be helped to recognise possible signs of difficulties for children aged 0-6 years through specific educational tools? These are some of the questions from which the study has developed.

The research structure takes different levels into account.

\section{Phase 1}

Drawing on the findings of current Neuroscience research, and on the EU Recommendation about the importance to ensure high-quality preschool education services, the research group has lead an investigation into the theoretical and practical foundations of pedagogical intervention in an Italian network of educational preschool services 0-6 year old (Happy Child Network). In particular, we carried out a qualitative analysis methodologically based on the innovative pedagogical framework developed by this network of Nursery schools and Kindergartens;

Subsequently, an assessment of cognitive, motor, linguistic and relational skills acquired by children attending the Happy Child network has been carried out. These areas are a fundamental part of the Happy Child educational method. In order to create an appropriate educational setting, it is important to understand the specific characteristics of the child's learning process (0-6 year-old) (Kuhn \& Pease, 2006). In this period, in particular, the child learns through direct, concrete and tangible experiences: it is essential, therefore, to build educational projects that consider this natural inclination towards learning.

Another important step of the first part of this research is represented by the identification of the satisfaction degree of different stakeholders (educators, coordinators, and parents).

\section{Phase 2}

Following the results achieved in the first steps of the research, a second phase has been carried out with a further sample of nurseries and kindergartens (FISM-Italian Preschool Federation-Parma). This phase includes four research actions:

(1) Educators' training needs were analysed in three macro-areas: to know (theoretical knowledge); to do (practical skills) and to be (personal and relational skills) (see Figure 1);

\footnotetext{
${ }^{2}$ Happy Child is an Italian network of Nursery schools and Kindergartens that has developed an innovative pedagogical framework based on the principles of a positive and in-time education; FISM is the Italian Federation of Catholic Kindergatens (in this research project we have collaborated with the FISM Parma section).
} 
(2) Specific training courses were designed and delivered to meet the identified needs;

(3) Identification of key-abilities in different areas of child development (age groups: 12-18 months;18-36 months; 3, 4, 5 years old) that could represent warning signs of disorder or difficulty;

(4) Developing educational observation tools in order to help educators and teachers to recognise early signs of disorder or difficulty.

In summary, the second phase aims to understand the training needs of educators and teachers in order to support their daily educational activities, and to develop pedagogical tools for early identification of difficulties in pre-school children.

A recent study conducted on a sample of 274 families with children with autism spectrum disorder (Maggiolini, 2016) revealed that Nursery and Kindergarten's teachers, in addition to their parents and relatives, are amongst the first figures to recognise and point out the warning signs of autism. In particular, if we examine the responses concerning pupils who have attended pre-school services, we can observe an interesting result: in the period 1994-1998, the teachers could notice signs of unusual behaviour around the child's fourth year. Nowadays (2009-2013), it is possible to recognise any "warning signs" from about 18 months of age, thus significantly earlier than in the past.

In conclusion, education professionals have a very important role in identifying these signs as soon as possible and in appropriately communicating with family; at the same time, those who reflect on these issues (specialists and researchers) have a great responsibility to support their practical work.

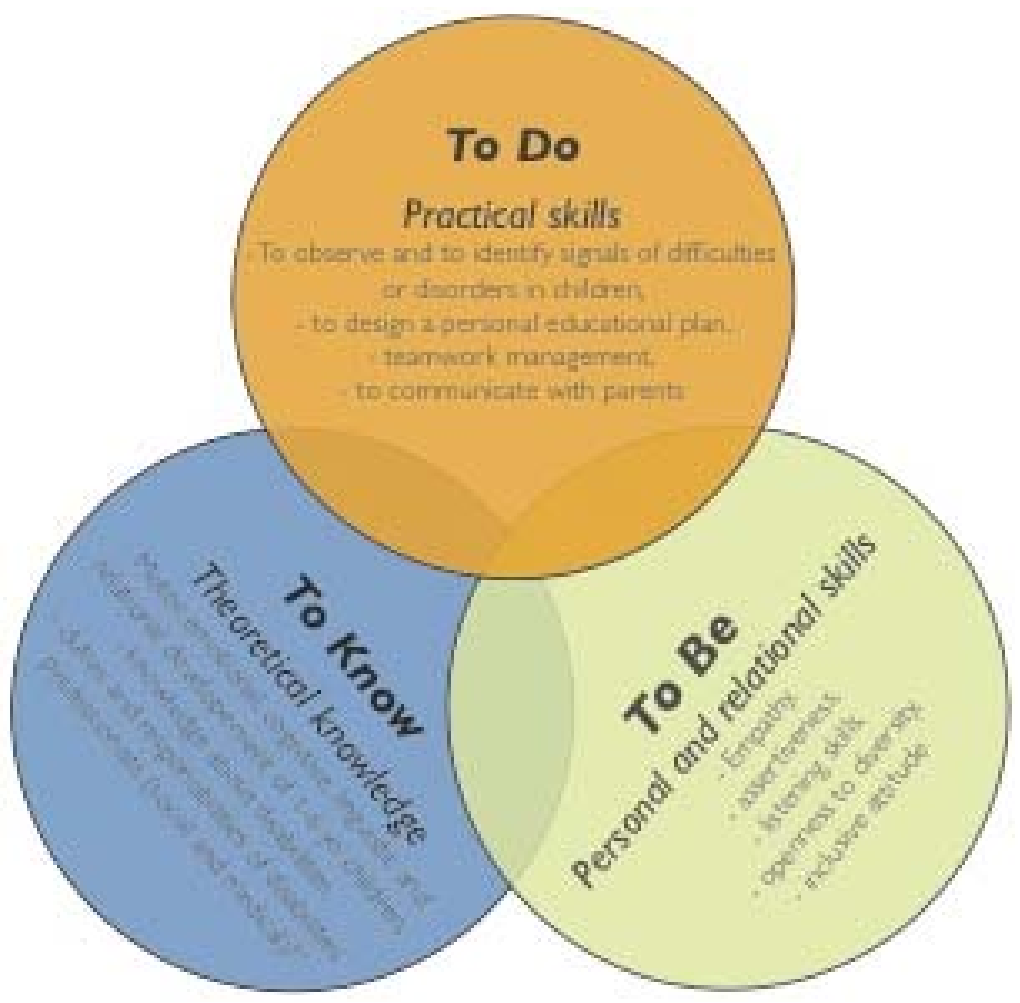

Figure 1. Training needs macro-areas.

\section{Results and Discussion}

In this section, we present the most important findings achieved in the two phases of research. 
As evidenced by studies in Neuroscience, the first years play a crucial role in the cognitive, linguistic, social, emotional and relational development of a child. The brain structure is very plastic during this period and the impact of experiences on brain development is remarkable. Based on this assumption, Happy Child, Italian network of Nursery schools, has developed a pedagogical method based on "timely" and "positive" education principles.

The child is offered the opportunity to engage in a positive relationship with the adult educator and to learn naturally by listening, observing, exploring and moving within an environment designed on his/her needs. The child's learning is based on direct experience: (s)he has a great desire to seek and to explore all the stimuli that the environment provides as if there were no time to lose (Burns, Donovan, \& Bowman, 2000).

The "timely" education principles are based on the importance of the time dimension and the natural evolution of a child (Aranda, 2008). Throughout his/her childhood, the child is continually "chased" by adult requests: often, adults are keen to accelerate the child's skills development, also anticipating the ordinary evolutionary stages. It is therefore important to respect, from birth, the child's natural slowness, his/her spontaneous repetitions.

The "positive pedagogy" framework emphasises the importance of educational interventions based on praising positive behaviour and aimed at encouraging all attempts to experiment in every growth's area.

Research studies linked to the principles of positive pedagogy have analysed the role of education in the child's progressive development of confidence in him/herself and trust in other people (Chen \& Namee, 2011; Masten \& Gewirtz, 2006). In the first years of life, it is particularly important to promote positive behaviours, because both the feeling of altruism and the ability to understand emotional and psychological states of people begin to develop in this period (Fredrickson, 2000).

This is the pedagogical framework of the Happy Child innovative educational method, which is based on:

(1) Educational activities in four different areas: linguistic (the acquisition of a foreign language through multi-sensory experiences that meet the learning needs in children 0-6 years old); mathematical (recent studies highlight the relationship between the quality of early experiences and maths performance in school years); musical (the early musical experiences have a positive effect on brain development: visual, tactile and motor areas are involved); and neuro-motor (psycho-motor activities are essential for body awareness and awareness of the surrounding space);

(2) Bits: visual stimuli are offered to children with specific frequency, intensity and duration during the day. The goal is to reinforce the children's natural interest in the world around them;

(3) "Tutorials" as a form of relationship between school and family in order to promote the educational co-responsibility.

The second phase of the research process has led to different important considerations.

First of all, it is important to analyse educational training needs as a complex set of abilities in three macro-areas: the theoretical knowledge (what I know), the practical skills (what I can do) and the personal and relational skills (what I am). In fact, by enhancing educators' skills it is possible to enable appropriate early intervention on children with disorders (e.g., autism spectrum, intellectual disabilities, genetic syndromes, etc.).

On this basis, specific training courses were designed and implemented in order to meet the identified needs. In particular, the courses focused on: the role of observation in early childhood services; the management of complex groups; the school-family relationship; the educational team, and the relationship with other professionals. 
A very significant step in the research process is represented by the definition of a pedagogical tool that enables educators and teachers to better understand dysfunctional behaviours or signs of difficulty in different developmental areas of a child.

The research group, drawing upon the expertise of a number of professionals (educators, researchers, teachers and a neuropsychiatrist), produced a couple of working tools: an initial (baseline) observation sheet and "the observation notebook".

It is important to note that both tools have purely pedagogical aims. On the one hand, they intend to offer scientific support to educators' and teachers' reflective thinking, helping their understanding of the child's behaviour within the schooling context. On the other hand, they aim to promote true co-responsibility with the family in order to define and agree on possible intervention plans (teaching practices, requests for a specialist assessment and referrals to regional services).

We believe that the true value-added dimension of our research project resides in the latter: the attempt to overcome the limitations of many observation protocols used in schools, which-due to logistical issues or lack of a systemic approach—run the risk of being marooned in a purely descriptive dimension. CeDisMa's working tools, on the contrary, are fundamentally aimed at enabling an early intervention through a timely identification of possible "alarm bells"; moreover, they intend to support the family with any necessary diagnosis and referral to social and medical services.

We also believe it is essential to emphasise the fundamental principle that has guided our research: "the requirement to respect the individual children's unique developmental differences, despite the use of any standardised grid" ${ }^{3}$

In order to adapt each tool to the child's specific age band, a number of products have been designed: three early observation sheets and three notebooks for nursery children (12-18 months; 18-24 months; 24-36 months); two observation sheets and two notebooks for pre-school children (3-4 years; 5-6 years).

In detail, the first assessment phase intends to identify early emerging dysfunctional aspects within the classroom context by using a simple and concise sheet. Its specific layout allows therefore the collection of essential information in order to systematise the observation process: contextual characteristics (activities, times, places); behavioural situations which, for different reasons, raise suspicion in educators and teachers (see Table 2).

Table 2

Early Observation Sheet (24-36 Months)

\begin{tabular}{|l|l|l|l|l|l|l|l|}
\hline Activity & \multicolumn{2}{|l|}{$\begin{array}{l}\text { Children } \\
\text { whose } \\
\text { behaviour } \\
\text { differ from the } \\
\text { group’s }\end{array}$} & $\begin{array}{l}\text { How children } \\
\text { carry out the } \\
\text { activity }\end{array}$ & $\begin{array}{l}\text { Unusual } \\
\text { behaviours } \\
\text { recorded }\end{array}$ & $\begin{array}{l}\text { How many } \\
\text { times this } \\
\text { behaviour has } \\
\text { been recorded } \\
\text { previously }\end{array}$ & $\begin{array}{l}\text { Level of } \\
\text { concern }\end{array}$ \\
\hline & Project & & & & & \\
\hline
\end{tabular}

* Unusual behaviours are defined as follows: behaviours that differ from the ordinary group's ones; behaviours that do not match a child's typical skills for his/her age; behaviours that could be significant.

It is interesting to emphasise the innovative elements of this tool: in order to avoid the not-infrequent risk of sensationalism, the educator/teacher is asked to endeavour to translate his/her perception of concern by

${ }^{3}$ Due to research issues, the tools are only partly described. 
making a choice between symbolic indicators (one lightbulb—-"monitoring needed”; two lightbulbs_-“careful monitoring needed”; three lightbulbs_-“I am concerned”; four lightbulbs_-“I am very concerned!”). A second noteworthy element of the sheet is the possibility of sharing the observations with the team, utilising it as useful guidance. There is also a summary section — to be filled in by the educational group-intended to represent not any particular individual voice, but to express the collective voice of the entire educational team. On this collective basis, it is possible to continue the journey into the fine details of the collected data by using a second tool— the "observation notebook" — which is aimed at analysing the child's emerging difficulties with regards to the outcomes of a particular age-phase.

Each of the outcomes is made up of different items, structured around four developmental areas (movement, communication, interpersonal relationships and emotional dimension; learning and application of knowledge), which describe predictable levels/objectives within a certain time period (see Figure 3). For each indicator, one is required to note its frequency and possible level of concern. As with the early observation sheet, the notebooks too have a summary section in order to compare, share and mediate its outcomes within the team.

Movement

1.1 Walks confidently
1.2 Climbs up the stairs using alternate feet
1.3 Jumps from different heights
1.4 Can climb up
1.5 Can co-ordinate gross motor skills without falling or stumbling
1.6 Can imitate gaits and movements
1.7 Can perform mixed motor trails adequately
1.8 Drinks without spilling and uses fork and spoon correctly
1.9 Uses puzzles and accuracy games
(pegs, shapes, beads, construction toys)
1.10 Handles markers and brushes adequately
1.11 Can put on socks and shoes
1.12 Can wash and dry own hands
1.13 Uses fine motor skills adequately
(cutting, gluing, colouring inside spaces)
1.14 Touches his/her fingers with the thumb - sequentially
1.15 Handles different materials
(crayons, playdough, flour, semolina, sand, water)

Figure 3. Movement area (Observation notebook: 3-4 years).

We strongly believe that having tools that encourage educators and teachers to note down significant information pertaining to a child's education is highly valuable as it supports an observation process aimed at monitoring the development of certain behaviours.

There are several reasons for this: first and foremost, the need to identify and promote the scientific profile of the education profession (across the phases), with its ever-increasing responsibility, especially with regards to its impact on the quality of life of children and people with difficulties. Secondly, the importance of implementing one of the fundamental principles of SEND pedagogy—early intervention—so as to design 
strategies aimed at responding to the specific needs of the disability. Last but not least, the setting-up of a relationship based on co-responsibility, genuinely rooted in network collaboration where all the agents engaged in the child's educational journey (educators, families, specialists) are able to contribute in their own specific way, supporting and valuing one another.

\section{Conclusion}

The need to ensure high-quality preschool education services is a priority goal in European educational policies and welfare. In order to promote the development and enhancement of these agencies, it is important to guarantee not only the achievement of quantitative parameters ${ }^{4}$, but also—and mainly—of qualitative improvement.

"Quality" is a wide concept, which includes many aspects: professional skills, the well-being of all stakeholders, the balanced management of resources, and the definition of evaluation systems.

In this respect, the results of this research lead to some important findings:

The need for a methodological, organizational, structural and scientifically-based framework as a fundamental requirement for planning educational activities in 0-6yo services. In particular, this research has investigated the "positive" and "timely" education principles, rooted in experimental evidence supported by international studies.

The role of continual training of educators and teachers as a key element to develop pedagogical skills for the early diagnosis and identification of disorders and difficulties in preschool children.

The importance of the relationship between different educational networks (nursery, kindergarten, family, social and health institutions) in order to promote a common responsibility.

In regards to this, a very important aspect is represented by the possibility of promptly identifying signs of difficulties from the very first years of a child's life. In response to this need, CeDisMa research group has designed and tested a toolkit capable of offering scientific support to the education profession and, at the same time, able to encourage teachers (especially Early Year Practitioners) to develop essential observational skills.

\section{References}

Aranda, R. E. (Eds.) (2008). Atención temprana en education infantile. In L. R., Wolters Kluwer, L., d’Alonzo, F., Bocci, \& S. Pinnelli (2015), Didattica speciale per l'inclusione, Pensa Multimedia, Lecce.

Kluwer, L. R. (2008). In Burns, M. S., Donovan, M. S., \& Bowman, B. T. (Eds.). (2000). Eager to learn: Educating our preschoolers. National Academies Press.

Chen, G. Mc, \& Namee. (2011). Positive approaches to learning in the context of preschool classroom activities. Early Childhood Education Journal, 39.

EU Recommendation 92/241/EEC.

Fredrickson, B. (2000). Cultivating positive emotions to optimize health and well-being. Prevention and Treatment, 3(1).

Guralnick, M. J. (2016). Early intervention for children with intellectual disabilities: An update. Journal of Applied Research in Intellectual Disabilities.

Kuhn, D., \& Pease, M. (2006). Do children and adults learn differently? Journal of Cognition and Development, 7(3).

Johnson, B. (2016). Early intervention in children with developmental disabilities. BMH Medical Journal, 3(1).

Maggiolini, S. (2016). Family associations and autism spectrum disorders: Outcomes from a research. Italian Journal of Special Education for Inclusion.

\footnotetext{
${ }^{4}$ The European Council in Lisbon (23-24 March, 2000) and the next summit in Barcelona (2002) highlighted the need for European Countries to promote the achievement of a 33\% threshold in the coverage of early childhood education services. The failure to achieve the target has led to reaffirm this priority in the Framework Programme Research and Innovation Horizon 2020.
} 
Maggiolini, S., \& Molteni, P. (2013). University and disability: An Italian experience of inclusion. AHEAD Association, 26(3), 249.

Masten, A. S., \& Gewirtz, A. H. (2006). Resilience in development: The importance of early childhood. In Encyclopedia on Early Childhood Development.

National Scientific Council on the Developing Child. (2007). The timing and quality of early experience combine to shape brain architecture (Working Paper 5). Center on the Developing Child at Harvard University.

Rushton, S., Rushton, A. J., \& Larkin, E. (2010). Neuroscience, play and early childhood education: Connections, implications and assessment. Early Childhood Education Journal, 37.

Schiller, P. (2010). Early brain development research: Review and update. Brain Development, 3.

Shonkoff, J. P. (2010). Neuroscience and the future of early childhood policy: Moving from why to what and how. Neurons, 67, 5.

Shonkoff, J. P., Phillips, D. (2000). From neurons to neighbourhoods: The science of early childhood development. National Research Council and Institute of Medicine, Washington, D.C..

Stanulis, R. N., \& Manning, B. H. (2002). The teacher's role in creating a positive verbal and nonverbal environment in the early childhood classroom. Early Childhood Education Journal, 30(1). 